\title{
EDUCAÇÃO E DIREITOS HUMANOS
}

\section{Marlene Rodrigues}

- Especialista em Psicologia Social e da Educação.

- Técnico Superior em Planejamento de Ensino da Universidade Federal de Mato Grosso do Sul.

Escrever ou falar de direitos humanos é reconhecer que o homem única e simplesmente por ser humano tem un direito inerente e inalienável: o de ser integralmente humano e, decorrente desse direito essencial, o direito de ter desenvolvida e preservada a sua íntima humanidade.

Ser humano constitui a mais profunda aspiração de dignidade que o homem pode sonhar. Significa ter direitos fundamentais: o direito à vida e à liberdade, ao trabalho e à segurança, ao amor e à razão, ao conhecimento e à tranquililidade, à paz, enfim.

Ter direito à vida não significa apenas viver, fato irreversível para quem nasceu e ainda não experimentou a morte.

Ter direito à vida significa viver com qualidade, ter possibilidade de desenvolver a própria personalidade, ter seus potenciais físicos e de inteligência e afetividade em permanente crescimento; ter condições intelectuais e 
afetivas para discernir e fazer escolhas; ter, enfim, possibilidades de construir o pröprio destino e governar a própria vida.

Viver com essa dignidade significa existir e "existir é eançar-se no mundo", 1 è fazer-se pessoa, é ser livre, a despeito dos conhecimentos, das tradições, da história, da morte e de todas as limitações humanas.

0 homem existe justamente porque se transcende, porque se dá sentido, persegue objetivos, cria e desenvolve valores.

"O que se chama vitalidade, sensibilidade, inteligência não são qualidades realizadas simplesmente, mas uma maneira do homem lançar-se no mundo e de desvendar-se como ser".

\section{Que Significa Ser Humano?}

Cada um de nös é dotado de uma natureza interna, limitada em certo sentido e, em certo sentido, invariảvel. E esta natureza que nos torna todos semelhantes.

Também é esta natureza --- sempre em evolução--que nos torna diferentes uns dos outros.

Temos necessidades fundamentais, não só de sobrevivência pura e simples, como o atendimento às nossas carências fisiológicas, mas de integridade mental e afetiva.

Para atender essas necessidades de natureza essencialmente psíquica, precisamos de segurança, de afei- 
ção, de oportunidades de desempenho e singularização, de autonomia e de interação com as outras pessoas.

Mais do que isso, temos necessidade de crescer em todas as dimensões --- não só o corpo, a inteligência e a qualidade das emoções --- mas tambêm a nossa amplitude dentro do mundo e o nosso poder de transformá-1o para melhor.

Como esta natureza humana parece ser neutra em relação à questão do Bem e do Ma1, é pré-moral e tem necessidade de crescimento, torna-se necessário que se incentive a sua expressão.

A carência humana, se negada, cerceada, reprimida ou eliminada, torna-se doente, por vezes de maneira óbvia, outras de modo sütil e camuflado. As vezes, percebe-se a tempo. Outras, tarde demais. 2

E quando isto acontece, e para a maioria das pessoas desgraçadamente tem acontecido, a busca de sentido torna-se impossíve1 e a pessoa humana desaparece para dar lugar a uma máscara, que não sabe de si, não sabe fazer escolhas, não se reserva um lugar no mundo, não sabe dos outros, se angustia ou é indiferente ou torna-se má.

Estar vivo e ser pessoa significa estar sendo atendido em suas necessidades mais fundamentais e ter em crescente e contínuo desenvolvimento a dimensão humana.

Isto, em outras palavras, significa um sentido para a existência. Significa saúde e integridade.

As pessoas sadias satisfazem suficientemente suas necessidades de segurança, amor e filiação. Nem mais nem 
menos. Não são obsecadas por estabilidade de qualquer natureza, nem perseguem o amor com desespero, nem desejam se ver continuamente acarinhadas, nem precisam manter-se dependente de nenhum grupo, pessoa, sentimento ou idéia.

As pessoas sadias são profunda e naturalmente 1ivres. Percebem a realidade exterior com grande alcance, rapidez e fidelidade. Estão mais próximas da Verdade e da Justiça, porque respeitam a própria humanidade como seu único e máximo valor.

Estas pessoas, raras no mundo de hoje, vivem em permanente processo de realização das próprias potencialidades, o que thes permite uma crescente autonomia e resistência a qualquer processo de condicionamento social e cultural.

Por causa desta liberdade interior, as pessoas em processo de individuação manifestam uma aceitação sempre maior de si, dos outros e da natureza. Reverenciam a vida em todas as suas manifestações e apresentam-se mais originais não sô nas criações, mas inclusive no modo de viver.

A felicidade, para elas, constitui-se num processo dinâmico em que a dor não está necessariamente eliminada, mas no qual a consciência tem um poder decisivo no que diz respeito à fruição da vida em geral.

Mais vitais e mais amantes da vida, tais pessoas manifestam maior espírito de democracia e fruem a beleza e a simplicidade, a sabedoria e a humanidade com mais intensa emoção. 
Sentindo-se Pessoa, tais pessoas sentem as outras da mesma maneira e, portanto, desejam para toda a humanidade o mesmo extraordinärio destino.

Quanto mais me encontro e quanto mais eu sou, as pessoas adquirem para mim uma dimensão ünica. Se eu sou, quero-as livres. Se eu sou, quero-as conscientes, amorosas $e$ criativas. Se eu sou, quero-as humanas, autodiretivas, transformadoras e em trans formação." 3

Ser pessoa significa, portanto, ser apaixonado.

A paixão é a necessidade de expressar nossas faculdades em relação ao mundo. Isto quer dizer que

porque tenho oltios, tenho necessidade de ver;

porque tenho ouvidos, tenho necessidade de ouvir;

porque tenho uma mente, tenho necessidade de pensar e de sentir.

Em suma, porque sou uma pessoa humana, tenho necessidade do homem $e$ do mundo. 4

Pão e Amor

Todos os homens têm o direito fundamental de crescerem não só fisicamente, mas também quanto aos seus potenciais intelectuais e à sua expressão afetiva. Isto quer dizer que todos os homens têm direito à satisfação de suas necessidades vitais básicas: alimentação, saúde, moradia, educação, lazer, amor, segurança, incentivo, justiça, ver- 
dade e paz.

O homem ê um ser que vive com totalidade. Ele precisa alimentar-se para ter seu corpo sadio, mas precisa alimentar-se tambẻm para ter sua mente sadia.

Em todas as partes do mundo, os cientistas têm anunciado farta e dramaticamente a íntima correlação existente entre o atraso mental e a desnutrição.

BALDWIN demonstrou que os escolares bem nutridos não só apresentam melhor desempenho intelectual, mas também maior nível de inteligência e WHIPPLE, depois de inúmeros estudos, concluiu que o precocidade intelectual é mais frequente entre crianças bem nutridas. 3

Entre os maiores prejuizos que a desnutrição e/ou nutrição inadeqứada podem acarretar para o desenvolvimento menta1, BLANTON relaciona a falta de energia física e nervosa, a falta de atenção, a memória prejudicada e compreensão deficiente e vagarosa. ${ }^{3}$

Além disso, os desnutridos apresentam baixa reatividade emocional. Isto significa, em linguagem objetiva, que para ser mais humano, o homem precisa de comida, boa comida, comida adeqǘada.

Jả é popular, ainda, que tambẻm para crescer e para ter sua inteligência desenvolvida, o homem precisa de amor .

Os médicos do Hospital John Hopkins, nos Estados Unidos, acompanharam treze casos de jovens que anresentavam estatura muito abaixo do normal e eram profundamente imaturos quanto a fala e ao comportamento. Eram ti- 
dos como deficientes mentais. Em algum ponto de suas vidas o desenvolvimento global tanto quanto emocional e intelectual havia sofrido uma atrofia. Um desses meninos tinha 4 anos e o médico sem nada suspeitar lhe dera aproximadamente um ano. Outro menino, de quase 12 anos, era de estatura menor do que a maioria das crianças com metade da sua idade. qual seria a explicação? os médicos comprovaram a inexistência de problemas alimentares $e$ as crianças não tinham herdado qualquer perturbação física. Entretanto, eram crianças emocionalmente perturbadas e que haviam sido negligenciadas pelos pais.

Ao serem colocadas em ambiente acolhedor e protetor, as crianças imediatamente passaram a desenvolver-se. Em menos de um ano, 0 garoto de 12 anos cresceu mais de 15 centimetros e engordou quase 20 quilos. Cada uma dessas crianças, ao ser colocada num orfanato, continuou a progredir. Mas as que retornaram ao convivio dos pais rejeitadores pararam de crescer $e$ perderam peso. 5

As principais características das crianças criadas em ambientes emocionalmente frios e desestimuladores ou carentes de incentivos são a falta de atenção, a palidez, c desânimo, a relativa imobilidade, o emagrecimento, o mutismo, a falta de apetite, evacuação frequente, aparência de infelicidade, sono insuficiente, ausência de reação aos estímulos afetivos, propensão para a febre e ausência de sucção. 3

A rejeição da criança por parte dos pais, sobretudo da mãe, é considerada como uma das mais provāveis causas 
dos comportamentọs esquizôides e da esquizofrenia propriamente dita. Sentindo-se abandonada, a criança

becha-se em si mesma, corta relações com o mundo e contra ele se revolta. Com esse mundo se desentende $e$ o atravessa cautelosa ou agressivamente, com a alma vazia de amor.6

"Liberdade, Abre As Asas Sobre Nōs!"

Viver livre é um direito fundamental.

A liberdade é a fonte de todas as significações, de todos os motivos, de todas as paixões da humanidade.

A liberdade não $\bar{e}$ minha nem tua. Ela não nos pertence. Pelo conträrio, e a liberdade que nos tem e nos protege. A liberdade $\bar{e}$ um ambiente em que se vive: por isso não $\bar{e}$ poss $\vec{i}$ vel haver um só homem livre numa sociedade sem liberdade. A liberdade invoca-se, propicia-se, mas nunca se a recebe de graça; pelo contrário, ela $\bar{e}$ que nos recebe e domina. E possivel fugir à liberdade, como quem foge de casa; $\bar{e}$ possivel impedir que outros vivam livremente, mas nãa $\bar{e}$ possivel nem ter nem impor a liberdade." 7

Querer-se livre é querer-se humano, pois o direito à liberdade abrange outros direitos: o direito de ser 
criador, o direito de participar, o direito de expressão, o direito de pensar e sentir de maneira própria e singular, o direito de agir e reivindicar, o direito de amar sem constrangimentos nem tabûs, o direito de viver livre do medo e da opressão.

Para gozar deste direito tão legítimo quanto essencial à sua integridade como Pessoa Humana, o homem precisa de uma sociedade humanizada e de viver num Estado 1ivre.

Entendo por sociedade humana e humanizada aquela em que o homem prevalece como o centro de todos os valores. Entendo por Estado livre aquele que se autodetermina face ao universo, desenvolvendo-se política, social e economicamente autônomo, jamais deixando desvanecer-se, na corrente das trocas internacionais, a sua cultura e os seus valores originais.

Em suma, os direitos podem ser dados aos homens por um governo, o qual é estabelecido com essa finalidade, recebendo do povo o poder de assim agir. Porém, ninguém tem o poder de dar a liberdade. Ela. existe ou não existe. Os governos podem e devem estabelecer as condições propicias à liberdade ou remover as condições que impeçam a sua vigência, mas nenhuma lei, por si só, pode estabelecer a liberdade, sem que sejam removidas as condições que a impeçam. Enfim, a democracia não será nunca bem sucedida se 0 povo que a estabelece $j \bar{a}$ não vive em plenas condiçoes de liberdade e não seja capaz de mantê-las." 1 
Lamentavelmente, os sistemas sociais e suas bases institucionais estão distanciados da experiência humana, dos anelos e das necessidades humanas. Perderam, na realidade, todo o contacto com a natureza humana.

A escola, a família e os sistemas de crenças de que as antigas ordens e organizações conceituais de outros tempos receberam apoio integral, não têm em nosso mundo a mesma realidade e, no entanto, ainda pesam sobre nós, massacrando a identidade pessoal e sufocando, quando não destruindo irreversivelmente, as forças criativas $e \circ$ poder humano de transformação.

Gradualmente, sem sentir, caimos na armadilha e nos tornamos "massa", absolutamente previsíveis, absolutamente moldáveis, destituídos de toda a liberdade e condenados à desumanidade.

A escola, a família e as religiões e, agora mais recentemente, os meios de comunicação às massas, funcionam como agências condicionadoras e mantenedoras de padrões de comportamento distantes da natureza humana. Ainda predomina nesses grupos o ideal da moral e da fôrma, a supremacia da autoridade, a idêia de formação do homem não pela consciência e pela sensibilidade, mas pela intimidação, o medo, as ameaças e punições.

Não se pretende educar, porque a tarefa mais legítima da Educação é justamente intensificar a consciência e a sensibilidade. O que se pretende ê a alienação, a robotização do homem às regras, o desvio e o sufoco às forças 
criativas, o desestímulo à capacidade real de pensar, de agir e de participar com autenticidade. 0 que se faz, na escola, inclusive com a cumplicidade da figura trágica do mestre, angustiado e conivente, é negar à criança, ao adolescente, ao jovem, ao homem em geral, a oportunidade simples, o direito elementar de ser integralmente humano.

Uma sociedade que agrilhoa a consciência social, que nega às pessoas direitos tão fundamentais, não sabe, ainda, reverenciar a vida. Não sabe sequer que a vida tem um sentido que, não obstante as poderosas forças do condicionamento e da alienação do homem, permanece intacto e acessive1 a todos os homens.

Só resta buscá-1o.

O Ensino dos Direitos Humanos

Cabe à Educação ocupar-se - em todos os níveis e graus — do ensino dos direitos humanos, afim de que a profunda aspiração dos homens à dignidade humana seja definitivamente preservada.

0 estudo dos direitos humanos deve ser exigido por todos como parte do currículo de todos os cursos.

Nas escolas de nível médio e nas universidades, estudantes e professores precisam reunir-se para a discussão dos direitos e liberdades fundamentais sem $\circ$ que não haverá jamais plenas garantias de que estejam em desenvol- 
vimento e de que realmente estejam sendo preservados.

o estudo dos direitos humanos ê fundamental para que se atinja, em todo o mundo, alto grau de consciência social. Para tanto, ê preciso que sejam estudados em todas as faculdades, não sô para que sejam conhecidos, o que por si sô jā ê um direito, mas também para que onsino se aprofunde e a pesquisa se amplie em benefício não sô das 1iberdades, mas também da melhoria imediata da qualidade de vida humana.

os efeitos dos progressos tecnológicos sobre o desenvolvimento e o exercicio integral dos direitos humanos precisa ser objeto sistematico de cientistas e educadores. E nas faculdades de medicina que se deve ensinar os direitos humanos em relação aos cuidados bãsicos da saūde, a preservação e manutenção da saūde, a prestação $e$ custo do atendimento médico,às experiências farmacolōgicas e genéticas, aos transplantes de ōrgãos, à utilização da psiquiatria e de outros ramos da medicina para bins não-médicos. 8

Nosso conhecimento das circunstâncias e causas que originam a fome, a pobreza, a doença, a tortura, o genocidio e a discriminação racial e religiosa ainda não são subicientes para prevenir ou eliminar esses males. Historiadores, sociólogos, economistas, engenheiros, psicōlogos, juristas e espécialistas em ciências politicas precisam encontrar as solu- 
ções para estes problemas. Filōsofos e teólogos, poetas $e$ artistas precisam e podem oferecer boas pespectivas sobre o apoio universal que seria concedido a certos conceitos dos direitos humanos fundamentais, tema que as pesquisas de ciências sociais até agora negligenciaram e que poderia ser estimulado se ensinado nas universida. des. 8

Tambēm é de vital importância o ensino dos direitos do homem em faculdades de educação, cursos de pedagogia, escolas normais, centros de educação especial, serviço social e biblioteconomia.

Se os futuros professores não conhecem os principios básicos, os problemas $e$ as soluções em matéria de direitos humanos, como poderão fazer cumprir nas escolas primarias - que determina a Declaração universal, ou seja, contribuir por meio da educação para o fortalecimento do respeito pelos direitos do homem e pelas liberdades fundamentais? As inūmeras violações dos direitos humanos que continuam ocorrendo $\mathrm{em}$ todo o mundo são uma triste e permanente lembrança da necessidade de se reforçar $e$ consolidar a educação do respeito aos direitos humanos $e$ as liberdades fundamentais. ${ }^{8}$

A defesa internacional dos direitos do homem, dada a sua importância, transcende divergências ideológicas, politicas e culturais.

Educar, Curitiba, 2(1):143-156, jan./abr., 1982. 
Ensinar o respeito aos direitos humanos - tanto os próprios como os alheios e ter coragem de afirmā-los mesmo nas circunstâncias mais dificeis $\bar{e}$ o maior imperativo de nossa época.?

Portanto, o estudo da Declaração Universal dos Direitos do Homem e o consequente ensino das liberdades fundamentais são indispensáveis a todo País que professe a fé incondicional na dignidade humana.

\section{NOTAS}

1 - BeAuvorr, S. Moral da ambigllidade, Rio de Janeiro, Paz e Terra, 1970.

2 - MASLOW, A. H. Introducão à psicologia do ser, Rio de Janeiro, Eldorado, 1973.

3 - RODRIGUES, M. Psicologia Educacional: uma crônica do desenvolvimento humano, 2 . ed., São Paulo, McGraw-Hill do Brasil, 1978.

4 - Fromm, E. A revolução da esperanga, Rio de Janeiro, Zahar, 1969.

5 - LEWIS, H. R. e LEWIS, M.E. Fenômenos psicossomáticos, Rio de Janeiro, Josë Olympio, 1974.

6 - DOURADo, L. A. Ensaio de psicologia criminal, Rio de Janeiro, Zahar, 1969.

7 - BUERGENTHAL, T. Desafio à Universidade, Correio da UNESCO, Rio de Janeiro, (12):dez. 1978.

9 - M'BOW, AM. A Cortina da Pobreza, São Paulo, Cia. Editora Nacional, 1979. 